Revista InterteXto / ISSN: 1981-0601

v. 10, n. 1 (2017)

\title{
O QUE A LINGUÍSTICA VARIACIONISTA DE WILLIAN LABOV LEU EM SAUSSURE SOBRE O CONCEITO DE FALA?
}

\author{
WHAT HAS WILLIAM LABOV'S THEORY TAKEN FROM SAUSSURE'S \\ SPEECH CONCEPT?
}

Breno Rafael Martins Parreira Rodrigues Rezende ${ }^{1}$

\begin{abstract}
Resumo: Neste trabalho, procedemos a um exame do movimento de teorização saussuriano a fim de refletir sobre o lugar da fala na teoria postulada pelo linguista genebrino, investigando a abordagem do conceito nas notas dos cadernos dos alunos (KOMATSU et. al., 1993; 1996; 1997) que frequentaram os Cursos de Linguística Geral ministrados em Genebra, que deram origem à edição de 1916 do Curso de Linguística Geral (CLG) organizado por C. Bally e A. Sechehaye. Além disso, nosso exame também se extendeu à edição do Curso ([1916]; 2012). Nós partimos da hipótese de que Saussure reconhecia a importância da fala para o estudo da linguagem, mas optou por desenvolver o conceito segundo o qual ele acreditava que todas as línguas poderiam ser estudadas de um ponto de vista científico. Nós percebemos que a questão da fala era sempre imposta ao pensamento do autor e que não raras vezes recebeu um tratamento teórico, embora não tenha sido uma noção tão desenvolvida como a noção de língua. Contrapomos esse exame a uma leitura de Labov ([1972]; 2008), reconhecendo que o lugar da fala na teoria de Saussure está condicionado a uma espécie de padrão epistemológico em que o estudioso investiu, além de parecer demonstrar que lidar com tal teoria demanda um exame cauteloso de um material demasiadamente vasto e complexo produzido pelo autor e que foi deixado de herança para a Linguística.
\end{abstract}

Palavras-chave: Saussure; Epistemologia; conceito de fala; conceito de língua.

Abstract: In this paper, we proceeded an examination of Saussure's theory, with the purpose of observing the place of speech in the theory postulated by this genevan linguist, investigating the concept's approach on the notes from the notebooks of the students who attended the General Linguistics Course taught in Geneva (KOMATSU et al, 1993;. 1996; 1997), which gave rise to the 1916 edition of the Course in General Linguistics organized by C. Bally and A. Sechehaye. In addition, our investigation also extended to the edition of the book Curso de Linguística Geral ([1916], 2012). We start from the assumption that Saussure recognized the importance of speech for the study of language, but chose to develop the concept that he believed that all languages could be studied from a scientific point of view. We realize that the issue of speech was always imposed on the thinking of the author and not infrequently received a theoretical treatment, although it was not a notion as developed as the notion of language. Counterpose this examination to a reading of Labov ([1972], 2008), recognizing the place of speech in Saussure's theory is subject to an epistemological pattern in which the scholar invested, and seem to show that dealing with such a theory demand a cautious take a too vast and complex material produced by the author and was bequeathed to linguistics.

Keywords: Saussure; Epistemology; speech concept; language concept.

\footnotetext{
${ }^{1}$ Mestre em Estudos Linguísticos pela Universidade Federal de Uberlândia (UFU). Bolsista de mestrado da Fundação de Amparo à Pesquisa do Estado de Minas Gerais (FAPEMIG).
} 


\section{Revista InterteXto / ISSN: 1981-0601 \\ v. 10, n. 1 (2017)}

\section{Introdução}

Sabe-se que as teorizações da chamada Linguística Moderna tiveram início nos primeiros anos do século XX com a publicação póstuma, em 1916, do Curso de Linguística Geral (CLG) cuja autoria é atribuída a Ferdinand de Saussure. A edição abarca, por exemplo, as ideias do genebrino em torno das especificidades da Linguística: seu objeto e o lugar da disciplina em meio às ciências humanas.

Saussure é comumente relacionado a apenas essa obra, embora, mesmo no pouco tempo de vida que teve, tenha publicado seu Memóire sur les voyelles e escrito milhares de páginas manuscritas que se encontram disponíveis na Biblioteca Pública e da Universidade de Genebra, na Biblioteca Nacional de Paris, na Biblioteca de Harvard e no Arquivo Científico e Acadêmico de São Petersburgo (KOMATSU e WOLF, 1996). As ideias do estudioso, que deram origem ao CLG, durante os três Cursos de Linguística Geral que ministrou na Universidade de Genebra, também estão eternizadas pelas anotações dos cadernos dos alunos que participaram de tais cursos e foram reunidas e editadas por diversos estudiosos como De Mauro, Engler e Komatsu (SILVEIRA, 2013). Além disso, hoje, muitos linguistas se debruçam sobre as ideias de Saussure e produzem em torno delas material teórico no Brasil e no mundo.

Um conceito que ainda provoca inúmeras polêmicas sobre a obra de Saussure é o conceito de fala. Silveira (2013) afirma que durante o século passado as leituras que se fez das ideias saussurianas são bem variadas e uma delas consiste na interpretação de que o genebrino exclui esse conceito de suas teorizações. Uma dessas leituras é a realizada por William Labov em Padrões Sociolinguísticos ([1972] 2008).

Neste artigo, procederemos a um exame sobre o lugar do conceito de fala na obra de Saussure fazendo contraponto ao que Labov critica ${ }^{2}$ em torno da "falta" de reflexões sobre a fala na edição de 1916. Para isso, valemo-nos da edição do CLG ([1916] 2012); da edição crítica de De Mauro (2005); e de

\footnotetext{
${ }^{2}$ Especialmente no capítulo 8, Estudo da língua em seu contexto social.
} 
algumas notas dos cadernos dos alunos do primeiro e do terceiro curso ministrados em Genebra, compiladas, editadas e traduzidas para o inglês por Komatsu e Wolf (1993), Komatsu e Harrys (1996) e Komatsu e Harrys (1997).

Partimos da hipótese de que, como os editores do CLG bem observaram no Prefácio à primeira edição (2012), assim como Silveira (2013), o conceito de fala não está excluído das reflexões de Saussure, mas o desenvolvimento de tal objeto pode ter sido interrompido pela morte prematura que o estudioso sofreu em 1913. Desse modo, longe da pretensão de dar conta do numeroso material que Saussure deixou de herança para os estudos dos campos da Linguística, investigaremos como o conceito de fala é apresentado no arcabouço teórico que a Linguística saussuriana delimitou, observando o movimento teórico ${ }^{3}$ a que o genebrino procedeu desde o primeiro curso até o terceiro, bem como a apresentação dos conceitos de língua, fala e linguagem tratados por ele e compilados na edição de 1916.

\section{A Linguística saussuriana e a delimitação de objetos teóricos}

A dificuldade de delimitar o objeto da Linguística já havia sido denunciada por Saussure desde 1893, segundo De Mauro (2005), e reafirmada em lições do segundo e do terceiro curso em Genebra, onde se lê no CLG: "Qual é o objeto, ao mesmo tempo integral e concreto, da Linguística? A questão é particularmente difícil" (2012, p. 39). Após quase um século da publicação da edição de 1916, é o que também afirma Borges Neto (2014) em capítulo sobre o objeto da Linguística.

Nesse capítulo, Borges Neto propõe uma reflexão sobre a delimitação de objetos teóricos que as diferentes áreas da Linguística constroem. Segundo o autor, corroborando uma das máximas saussurianas de que "o ponto de vista constrói o objeto", os diferentes campos de estudos dessa área têm como objeto observacional um "feixe de fenômenos", uma "região" da linguagem, a partir do qual, em cada arcabouço teórico que se mobilize, um "loteamento", ou

\footnotetext{
${ }^{3}$ Conceito apresentado por Silveira (2007) em trabalho sobre a complexidade do pensamento saussuriano a partir das rasuras dos manuscritos do estudioso.
} 
seja, um recorte, precisa ser criado, já que teorias diferentes "podem construir objetos teóricos distintos sobre um objeto observacional que é [pode ser] supostamente o mesmo" (op. cit., p. 37). É justamente esse o movimento teórico a que Saussure procedeu.

De acordo com Borges Neto (2014, p. 52), Saussure foi insistente na delimitação de um objeto homogêneo para a Linguística. Nas palavras do linguista:

[...] para Saussure, só é linguística o estudo que tomar por objeto a langue; tudo o mais fica fora do domínio dessa ciência. Certamente, Saussure entende que há mais coisas no fenômeno da linguagem além da langue, mas essas outras coisas são periféricas e dependem da langue para sua abordagem. A langue é a parte essencial da linguagem (destaques do autor).

A despeito de uma interpretação que pudesse ler, nas palavras de Borges Neto, qualquer adesão a uma tese simplista de que a teoria saussuriana fora fundada sob a égide da homogeneidade e que excluiria de todo modo a heterogeneidade dos fatos da linguagem, observamos que o autor parece constatar coisas distintas no movimento teórico a que Saussure procedeu: i) que o objeto da teoria Linguística postulada pelo genebrino é a língua (como se verá adiante, quiçá um objeto a partir do qual ele poderia ter feito abstrações em torno da outra parte da linguagem) e ii) que o estudioso reconhecia a linguagem, de fato, como um objeto heterogêneo, a partir do qual não poderia postular conceitos em torno de seu objeto "eleito" que é o sistema linguístico e as unidades psíquicas que o compõe: os signos. Observemos o que Borges Neto (2014, idem.) comenta em seguida:

Saussure pretende tornar a linguística, verdadeiramente, uma ciência. Para isso, é preciso homogeneizar de qualquer forma o objeto, uma vez que não é possível, no seu entender, descobrir as regularidades necessárias para o estudo científico da linguagem se a linguística não voltar sua atenção para um objeto homogêneo. Apenas a homogeneização do objeto permitirá descobrir nele a sua verdadeira ordem, uma ordem que ultrapasse a mera descrição e que permita chegar ao nível da explicação. A noção de langue tem, no quadro da teoria 
saussuriana, o papel de tornar homogêneo o objeto e permitir à teoria linguística aceder à explicatividade.

De nossa parte, parece-nos necessário especificar, a partir da diferenciação entre língua e fala na obra de Saussure, o tratamento que se tem dado à noção de "objeto homogêneo" no interior do arcabouço teórico construído por ele. Isso porque, aparentemente, algumas críticas feitas à elaboração teórica de Saussure parecem ter por base uma leitura do CLG que induz à consideração de que o objeto saussuriano é homogêneo, através da justificativa ele se desdobra numa equação "linguagem = língua - fala". Por outro lado, da maneira como assumimos, a delimitação do objeto da Linguística a que o genebrino procedeu recai sobre o fato de o linguista considerá-lo segundo sua própria natureza que, como veremos, é uniforme.

\subsection{Linguagem: "caveleiro de dois domínios"}

No capítulo III do CLG (2012), podemos afirmar que Saussure assumiu uma posição teórica que pode ser o "gatilho" para as acusações que o estudioso tem recebido ao longo dos anos em torno da problemática do conceito de fala. É, pois, neste capítulo que o genebrino considera a língua como o objeto de que a Linguística viria a se ocupar e que, apesar de ser constitutivo dela, não se confunde com a linguagem.

Para tal estudioso, a linguagem é um fenômeno que engloba naturezas diversas (física, fisiológica e psíquica), pois se reporta a um domínio individual e a um domínio social. O problema que a linguagem impõe à teorização saussuriana é justamente esse: sua natureza multiforme que, segundo Saussure, "não se deixa classificar em nenhuma categoria de fatos humanos, pois não se sabe como inferir sua unidade" (CLG, 2012, p. 41). Em nota sobre os manuscritos de Saussure referentes ao capítulo III da introdução do CLG, Godel (1969, p. 97) afirma que "le problème, à la fois théorique et terminologique, qui s'est posé à Saussure est, selon ses propes termes, celui de la classification logique des faits du langage et des points de vue sous 
lesquels on les traite" ${ }^{4}$, o que parece indicar que a dificuldade em atribuir um lugar para cada fato da linguagem é recorrente no movimento de teorização saussuriano.

A solução em que Saussure investiu foi considerar a língua como objeto a partir do qual todas as outras manifestações da linguagem poderiam ser estudadas, como aparece no CLG. Para o linguista, a língua, fenômeno social, oferece a vantagem de ter uma natureza única, pois é constituída pela relação psíquica de unidades de mesma natureza: os signos.

Não pretendemos, neste texto, dar conta da extensa discussão em torno dos conceitos de homogeneidade e de heterogeneidade que as reflexões saussurianas engendram, mas assumimos a hipótese de que o caráter homogêneo que Saussure dá à língua diz respeito a um objeto constituído por unidades de mesma natureza, ou seja, unidades necessariamente psíquicas. Em contrapartida, lemos no CLG que esse não é o caso da fala que, para o estudioso, é um ato individual que demanda um funcionamento fisiológico dos órgãos vocais, mas que também demanda questões físicas atreladas à propagação do som (além de questões psíquicas, já que a fala é subordinada à língua, como veremos ao longo deste texto).

Ademais, desde o primeiro Curso que Saussure ministrou em Genebra, em 1907, é possível perceber um movimento de sua teorização em definir o lugar da língua nos fatos da linguagem. Em As marcas do movimento de Saussure na fundação da Linguística (2007), Silveira, ao analisar as rasuras dos manuscritos saussurianos, observa que o pensamento do linguista genebrino é complexo e permeado por diversas reformulações. Apesar disso, o movimento de teorização a que Saussure procedeu tem como constante uma diferenciação entre os fatos da linguagem. Retomemos uma noção de língua e fala recuperada das notas do segundo caderno de Riedlinger do primeiro curso:

Cette opposition de langue et de parole <qui> nous est mise $<$ ici> dans la main, cette opposition est tres importante par la clarte qu'elle <jette dans> l'étude du langage. Un moyen de

\footnotetext{
4 "O problema, tanto teórico quanto terminológico, que se apossou de Saussure é, em suas próprias palavras, a classificação lógica dos fatos da linguagem e os pontos de vista a partir do qual eles são tratados" (tradução nossa).
} 
Revista InterteXto / ISSN: 1981-0601

v. 10, n. 1 (2017)

rendre particulierement sensible et <observable> cette opposition c'est d'opposer langue et parole dans l'individu (le langage est social il est vrai mais pour nombre de faits il est plus commode de le rencontrer dans l'individu). On pourra alors distinguer presque tangiblement ces deux spheres: langue et parole: tout ce qui est amene sur les levres par les besoins du discours et par une operation particuliere: c'est la parole. Tout ce qui est contenu dans le cerveau de l'individu, le depot des formes <entendues et> pratiquees et de leur sens: <c'est> la langue (KOMATSU e WOLF, 1997, p. 65) .

Ao assumir a língua como fenômeno do domínio social, já no primeiro curso, Saussure parece observar a necessidade de que sua teoria possa dispor de um objeto que apresente a vantagem de enssejar regularidades para 0 estudo (um objeto concreto cujos elementos sejam de mesma natureza). Dizemos isso com base na diferenciação a que o linguista procede, colocando a fala para as necessidades do indivíduo e atribuindo à língua o lugar de convenção social, cujas entidades que a compõe estão "contidas no cérebro" dos indivíduos.

No CLG (2012, p. 45), observamos que a realização da fala é "sempre individual e dela o indivíduo é sempre senhor". Por outro lado, a língua é regular no cérebro dos falantes de uma mesma comunidade, é "um tesouro depositado pela prática da fala por todos os indivíduos pertencentes à mesma comunidade, um sistema gramatical que existe virtualmente em cada cérebro ou (...) nos cérebros dum conjunto de indivíduos" (2012, p.45). Para o estudioso, desse modo, a língua (enquanto princípio de regularidade) não está completa em um só indivíduo, "só na massa que ela existe de modo completo" (idem).

Tal reflexão corrobora a afirmação de Borges Neto (2014) de que Saussure assumiu a necessidade de estabalecer um objeto para que sua teoria fosse alçada ao lugar da Ciência, mostrando como o genebrino,

\footnotetext{
5 "Esta oposição entre língua e fala que temos aqui em mãos é muito importante para a clareza em torno do estudo da linguagem. Uma maneira de tornar particularmente sensível e observável essa oposição é opor a língua da fala no indivíduo (a língua é social, mas é verdade, para muitos dos fatos, que mais conveniente é atrelá-la ao indivíduo). Podemos então distinguir quase tangivelmente essas duas esferas: lingua e fala: tudo o que traz para os lábios por efeito de necessidades do discurso e por uma operação específica: é a fala. Tudo o que está contido no cérebro do indivíduo, as formas de depósito, ouvido, praticado e o seu significado: é a língua" (tradução nossa).
} 
aparentemente, estava preocupado com padrões espistemológicos; mostrando a necessidade que ele observou em estabelecer as diferenças entre língua e linguagem para dar à Linguística seu objeto teórico. De acordo com Camacho (2010), essa preocupação também se mostra quando Saussure, no CLG, compara a Linguística com outras áreas do saber, afirmando que, ao contrário de outras ciências, o objeto desta área não se apresenta com facilidade.

No entanto, mesmo no afã de construir o objeto da Linguística tomandoo a partir da construção do conceito de língua, para Silveira (2013), Saussure afirma no CLG que a língua observada de seu aspecto diacrônico só pode realizar-se por manter relação com a fala, assim como a fala é dependente da língua. De acordo com a linguista (2013, p. 50):

Vemos aqui Saussure partindo da concepção de fala própria ao
seu ambiente de formação: fisiológica/física,
psicológica/psíquica e individual, e reformulando o conceito a
partir da sua necessidade de conceituar também a língua. A
fala, no seu aspecto empírico, fisológico e individual, é
secundária na consituição do objeto da Linguística. A fala, no
seu aspecto psíquico e social, é o que constitui a língua e é o
essencial ao objeto da Linguística.

Desse modo, na esteira das afirmações de Silveira, acreditamos que ao "eleger" a língua como objeto central de sua teoria, Saussure não exclui a fala dos fatos da linguagem e de sua empreitada de pesquisa, mas assume que ambos os fenômenos estão intrinsecamente ligados numa relação de dependência, o que o levou a formular hipóteses em torno de uma "Linguística da fala" e de uma "Linguística da língua", o que discutiremos a seguir.

\subsection{Duas Linguísticas: a da fala e a da língua}

Para Saussure, como se lê no CLG (2012, p. 50), estabelecer o lugar da língua em meio aos fatos da linguagem permite situar "ao mesmo tempo toda a Linguística". O estudioso assume que todos os fatos da linguagem subordinamse à língua, mas não implica dizer que eles são fatos exteriores à Linguística; é 
graças a essa tal subordinação "que todas as partes da Linguística encontram seu lugar natural" (2012, p. 50).

Segundo o genebrino, a fala tem um lugar específico na Linguística, já que sua possibilidade se dá pela relação inextrincável que mantém com a língua. Para o estudioso, "a língua é necessária para que a fala seja inteligível e produza todos os seus efeitos; mas esta é necessária para que a língua se estabeleça; historicamente, o fato da fala vem sempre antes” (CLG, 2012, p. 51).

Mais adiante no CLG, na parte dedicada à mutabilidade do signo, observamos que a língua, em seu aspecto diacrônico, sofre mudanças por intermédio da massa falante e a ação do tempo, corroborando a ideia (talvez não amplamente desenvolvida) de que Saussure observou na fala um papel importante para a Linguística, mas se ocupou primeiramente em conceituar a língua como unidade central no estudo do sistema herdado por todos os indivíduos de uma mesma comunidade de fala.

Nas notas de Constantin, do terceiro curso de Linguística Geral ministrado por Saussure em Genebra, principal material para a elaboração da edição de 1916, segundo os próprios editores e como fora lembrado por Altman (2013), notamos que assumir a língua como objeto de estudo não implica uma exclusão da fala das reflexões saussurianas, já que não é possível concluir que "dans la Linguistique de la langue il ne faut jamais jeter de coup d'ceil sur la Linguistique de la parole"6 (KOMATSU e HARRYS, 1993, p. 92).

Além disso, nessa mesma nota do caderno de Constantin, podemos analisar que o pensamento saussuriano ainda era permeado de muitas dúvidas sobre a questão que dividia Linguística da língua e Linguística da fala: "Maintient-on le nom de linguistique pour les deux choses réunies, ou faut-il le réserver à l'étude de la langue [?] "' (idem.). Assumimos que a interrogação na nota pode ser relativa a um tom de dúvida que Saussure possa ter "imprimido" sobre a questão ao apresentá-la em aula. Se a resposta fosse sim para

\footnotetext{
${ }^{6}$ (...) a Linguística da língua nunca jogue seu olhar sobre a Linguística da fala (tradução nossa).

${ }^{7}$ Mantemos o nome de Linguística para as duas coisas reunidas ou reservamos apenas ao estudo da língua [?] (tradução nossa).
} 
estabelecer o nome de Linguística para as duas coisas, poderíamos nos indagar quanto a distinção entre o lugar da língua e da fala nos fatos da linguagem, distinção que, como já dito, parece ter sido uma das preocupações primordiais do estudioso desde o primeiro curso.

Como se vê, Saussure estava preocupado em "marcar" a diferença entre língua e fala, mas isso não implica a exclusão do segundo conceito em detrimento do primeiro, pelo contrário. O pensamento do estudioso é complexo e, assim como observou Silveira (2007), passou por diversas reformulações até chegar na fase mais "madura" no terceiro curso: observamos que a diferenciação entre os dois conceitos é latente no movimento da teorização saussuriana, mas a existência de uma langue como um sistema de signos partilhado pelos indivíduos de uma comunidade de fala não oblitera a importância que a parole representa para que tal sistema possa "evoluir" - no sentido de mudar, sentido que assumimos a partir da leitura a que procedemos em torno da obra do genebrino.

Nessa perspectiva, entendemos que atribuir um lugar para a língua e outro para a fala não se trata de excluir uma ou outra do arcabouço teórico em que investiu para a constituição de um campo, e sim de escolhas epistemológicas centradas em decisões teóricas que são impostas a todo e qualquer pesquisador: a leitura dos materiais que apresentamos até aqui parece demonstrar que o conceito de fala é intrínseco a formulação da teoria do sistema de signos que Saussure postulou, embora não tenha sido um conceito tão desenvolvido, talvez pelo fato de o terceiro curso, que representa, como já dito, a fase mais madura do pensamento investigativo de Saussure, nunca ter chegado ao fim.

\section{Saussure em Labov}

O trabalho de Labov, apresentado em Padrões Sociolinguísticos (2008 [1972]), representa, indubitavelmente, muitos avanços para o tratamento de dados coletados da fala e também para uma teoria de variação e mudança linguística. Primorosamente, o autor apresenta um arcabouço teórico- 


\title{
v. 10, n. 1 (2017)
}

metodológico capaz de lidar com questões atreladas à fala (e não apenas), a partir da consideração de fatores externos à língua ${ }^{8}$, que envolvem o contexto de fala dos falantes "reais" das variadas pesquisas que se debruçam sobre questões que interessam a essa área da Linguística.

No entanto, a crítica apresentada pelo autor em torno da problemática langue/parole a partir de sua leitura sobre a obra de Saussure parece merecer algumas considerações. Labov afirma que os linguistas que trabalham numa concepção saussuriana se ocupam do caráter "social" da linguagem e obliteram o funcionamento da interação social propriamente dita, já que não poucas vezes se ocupam de um ou dois informantes ou de seu próprio conhecimento de língua para procederem às pesquisas linguísticas de dentro de seus próprios gabinetes. O autor ainda afirma que a justificativa para tal procedimento diz respeito às explicações de fatos linguísticos serem dadas apenas por fatos linguísticos, sem a consideração de qualquer dado externo ao comportamento da língua.

Observemos a nota em que Labov (2008 [1972], p. 217) comenta que

\begin{abstract}
Meillet, contemporâneo de Saussure, acreditava que o século XX assistiria o desenvolvimento da explicação histórica baseada no exame da mudança linguística encaixada na mudança social. Mas discípulos de Saussure, como Martinet, repudiaram ativamente essa opinião e empreenderam esforços para que a explanação linguística ficasse confinada às interrelações de fatores internos, estruturais. Assim procedendo, eles certamente seguiam o espírito da doutrina de Saussure, pois o estudo mais atento de seus escritos sugere que, para ele, "social" não significava muito mais do que "multiindividual", sem nenhuma sugestão das implicações mais amplas da interação social.
\end{abstract}

Vemos aqui uma leitura diferente daquela em que centramos nossa argumentação em torno do domínio social e individual que a linguagem abarca. Para Labov, o que é "social" na teorização saussuriana implica um conhecimento "partilhado" pelos indivíduos de uma mesma comunidade de fala e nisso concordamos com ele: para Saussure, como se pode observar no CLG

\footnotetext{
${ }^{8}$ Que tem como definição saussuriana, grosso modo, um sistema de signos, solidários entre si, partilhado pela comunidade de fala.
} 
(2012), a língua se reporta a um domínio social, cujos elementos são partilhados por uma mesma comunidade, mesmo se algum indivíduo dela tenha sofrido alguma lesão cerebral que o impeça de falar, já que se pode, por exemplo, "recitar um poema mentalmente".

Entretanto, aparentemente, para Labov, a noção de língua definida por Saussure é problemática, uma vez que, segundo o americano, não se reporta a nenhuma implicação da interação social; à fala. Entre outros argumentos que poderiam ser ditos contra tal afirmação ${ }^{9}$, optamos por enfatizar o movimento de teorização da linguística saussuriana: como tentamos demonstrar, Saussure parece ter se ocupado em delimitar um objeto regular para que sua teoria alcançasse as especificidades do campo da ciência, observando na língua a vantagem de poder ser apreendida como fenômeno de natureza única, diferentemente da fala ou da linguagem como um todo; observando a língua como um fenômeno regular.

Para o sociolinguista americano, no entanto, a língua, respondendo a um domínio social e a fala a um domínio individual, constrói um paradoxo ${ }^{10}$ : "o aspecto social da língua é estudado pela observação de qualquer indivíduo, mas o aspecto individual somente pela observação da língua em seu contexto social" (LABOV, 2008, p. 218). Por outro lado, do modo como apresentamos os conceitos saussurianos de língua e de fala, parece-nos, pois, que não há nenhum paradoxo: a língua pode ser observada em qualquer indivíduo, pois é regular, enquanto a fala está condicionada à realização individual da língua.

Afirmar que a diferenciação de língua e de fala, a que Saussure procedeu, culmina em um paradoxo, permite observar que Labov se posiciona a favor da ideia de que uma ciência da fala parece nunca ter sido matéria de preocupação do linguista genebrino. De fato, como já salientamos, o desenvolvimento de uma Linguística da fala parece nunca ter chegado ao fim. Porém, uma leitura atenta do numeroso material que Saussure produziu parece

\footnotetext{
${ }^{9}$ É possível observar, por exemplo, no CLG e nos cadernos dos alunos que frequentaram os cursos ministrados por Saussure em Genebra, que a "interação social" pode ser entendida como um dos fatores que possibilitam uma linguística geográfica, cujas especificações estão reunidas na quarta parte da edição de 1916; parte que é constantemente negligenciada por várias pessoas que se propõem a estudar a teoria de Saussure e também pelos diversos cursos de graduação e pós-graduação em Linguística distribuídos pelo país.

${ }^{10}$ Chamado por ele de paradoxo saussuriano.
} 
demonstrar como o genebrino estava preocupado com a questão e de que, possivelmente, seja possível ver em seu movimento teórico indícios de que uma tal teorização já estava sendo germinada, uma vez que a fala é, para ele, implicada na língua e vice-versa.

Em última análise, o tom crítico da leitura de Labov sobre os conceitos de língua e fala cria um invólucro em torno da teorização saussuriana, atribuindo a ela a noção de que "língua homogênea", segundo essa tal leitura, implica unicamente o fato de o objeto da Linguística se constituir em torno da língua considerada fora dos fatos da linguagem. Uma leitura como essa, no entanto, pode se mostrar parcial, uma vez que, assim como tentamos demonstrar, o caráter homogêneo da língua, para Saussure, parece mais dizer respeito a sua realidade uniforme, consituída pela natureza dos elementos que lhe são consitutivos e que é única, psíquica, enquanto a linguagem é multiforme: física, fisiológica, psíquica, social e individual.

Ao longo de um século, as reflexões de Saussure têm sido tomadas como objeto de inúmeras polêmicas e críticas, assim como a apresentada por Labov (2008). Reler a crítica do sociolinguista americano sobre as reflexões saussurianas se mostrou importante para esse estudo, uma vez que ela motivou o movimento de reflexão que empreendemos: considerar as teorizações de Saussure implica reconhecer seu movimento teórico, centrado na necessidade de estabelecer padrões epistemológicos capazes de criar um objeto para a Linguística, tarefa que o próprio genebrino considerou laboriosa (CAMACHO, 2010). Nessa perspectiva, parece-nos que a escolha de "eleger" a língua como o cerne de suas preocupações não implica a desconsideração da fala, e sim responder às perguntas que se impõem a todo pesquisador em processo de construção teórico.

\section{Considerações finais}

O breve exame a que procedemos em torno das noções de língua e fala na obra de Saussure permitiu considerar que o conceito de fala não se encontra excluído das ideias do genebrino, apesar de não ter tido o mesmo 
desenvolvimento que a noção de língua, assumida pelo estudioso como o objeto central de sua teoria. Antes de mais nada, tal exame tinha como pretensão promover uma leitura diferente daquela em que se afirma que a fala não tem nenhuma especificidade no arcabouço teórico saussuriano, já que, de todo modo, ela se encontra pelo menos germinada.

Nessa perspectiva, observamos, no material teórico mobilizado, que a preocupação de Saussure em estabelecer um lugar para a Linguística culminou numa diferenciação entre os fatos da linguagem, o que não implica dizer que todos eles, de um modo ou de outro, não colaboraram para que seu pensamento complexo pudesse criar uma teoria por meio da qual um sistema linguístico fora apresentado como regular para todas as línguas naturais.

É natural que uma teoria que fez com que o genebrino viesse a ser conhecido como o "pai" da Linguística Moderna circule e seja motivo de inúmeras polêmicas e também é natural, a partir de seu aspecto científico, que muitas leituras sejam feitas em torno dela. No entanto, hoje (muito mais do que na época em que Labov desenvolveu sua teoria da mudança e da variação linguística), contamos com materiais diversos que possibilitam, cada vez mais, que sejam lançadas sobre essa teoria olhares diferentes, a cada escrito novo que surge em torno da problemática que envolve a teoria saussuriana.

Assim, parece ser imperativo que qualquer leitura que emerja se volte a uma vastidão de conceitos, formulações e reformulações que se tem feito desde 1916. Como se sabe, o CLG é fruto de um trabalho magistral empreendido por C. Bally e A. Sechehaye em torno dos Cursos de Linguística Geral ministrados por Saussure em Genebra, mas sua teoria, sempre em processo de reformulação, como apontam as análises de Silveira (2007), merece sempre muita cautela, a cada manuscrito ou nota que se descubra em torno do pensamento saussuriano; parece necessário, então, que as afirmações feitas a partir de tal pensamento se reportem para além do CLG, buscando ver o movimento de teorização produzido pelo estudioso também em outros materiais, a exemplo de diversos pesquisadores, como Silveira (2007; 2013), De Mauro (2005), Komatsu e Harrys (1993), Komatsu e Wolf (1996;), Komatsu e Harrys (1997), entre tantos outros. 


\section{Referências}

ALTMAN, C. Sobre mitos e história: a visão retrospectiva de Saussure nos três Cursos de Linguística Geral. In: FIORIN, J. L.; FLORES, V. N.; BARBISAN, L. B. (orgs). Saussure: a invenção da Linguística. São Paulo: Contexto, 2013.

BORGES NETO, J. Do que trata a Linguística afinal? In: Ensaios de filosofia da Linguística. São Paulo: Parábola Editorial, 2004.

CAMACHO, R. G. Uma reflexão crítica sobre a teoria sociolinguística. In: Revista Delta. V. 26. N. 1. São Paulo: 2010.

DE MAURO, T. Cours de Lingistique Generale: Edition critique. Paris: Payot, 2005.

GODEL, R. Les source manuscrit du cours de linguistique generale de Ferdinand de Saussure. Genebra: Libraire Droz, 1969.

KOMATSU, E.; HARRYS, R. Troisieme Cours de Linguistique Generale. Oxford: Pergamon Press, 1993.

KOMATSU, E.; WOLF, G. Premier Cours de Linguistique Generale. Oxford: Pergamon Press, 1996.

KOMATSU, E.; WOLF, G. Deuxieme Cours de Linguistique Generale. Oxford: Pergamon Press, 1997.

LABOV, W. Padrões sociolinguísticos. São Paulo: Parábola, [1972] 2008.

SAUSSURE, F. Curso de Linguística Geral. 28 ed. BALLY, C.; SECHEHAYE, A. (orgs.). São Paulo: Cultrix, [1916] 2012. 
SILVEIRA, E. As marcas de Saussure na fundação da Linguística. Campinas: Mercado de Letras, 2007.

. O lugar do conceito de fala na produção de Saussure. In: FIORIN, J. L.; FLORES, V. N.; BARBISAN, L. B. (orgs). Saussure: a invenção da Linguística. São Paulo: Contexto, 2013.

Artigo recebido em 28/12/2016

Artigo aceito em 02/09/2017 